\section{A MARGINAL RESOURCE FOR CIVIC IDENTITY: THE INTERNET IN SWEDISH WORKING} CLASS HOUSEHOLDS TOBIAS OLSSON

Abstract

Within research as well as policy debates, much effort has been put into analysing the Internet's significance for democracy. These discussions have certainly contributed to progress in the area by, for instance, statistically pointing out the differentiated access to the new ICT among various social groups and - mainly theoretically - suggesting in what ways the Internet can become a tool for democracy.

However, these analyses also hold a few blind spots, of which this article discusses two. Firstly, they have paid only minimal attention to the everyday users' experience of new

ICT. Secondly, they have usually focused quite exclusively on the Internet rather than looking at it as part of an already-established media environment. This article is an initial effort to compensate for these shortcomings. It departs from the concept 'civic identity' and analyses qualitative data on Swedish working class users' use and perception of the Internet as well as 'traditional media.' For those who

believe the Internet to be an inclusive medium and as such a tool for democracy, the article's empirical results are somewhat discouraging. For instance, the empirical and analytical discussions reveal that the traditional media - TV, newspapers and radio - are far more important than the Internet to the working class users' civic identities.
Tobias Olsson, Department of Media and Communication Studies, School of Social Sciences, Växjö University; e-mail: tobias.olsson@vxu.se. 
Ever since the Internet made its breakthrough into the western world, about ten years ago (around the time when the first web browsers reached the mass market), much effort has been put into analysing new information and communication technology's (ICT) significance for citizens, for politics and - more generally - for democracy. Just a quick glance at the academic book market confirms that the new medium has become a veritable melting pot for ideas about changes in contemporary western democracies. Among the released books we find New Media and Politics, Virtual Politics and Democracy and New Media.

Of course, this has not just been an area of interest to social scientists. Comparable discussions have also been numerous within political as well as popular debates in Sweden. In popular debates, writers have quickly identified the Internet's capacity to strengthen democracy. In 1999 one prominent debater stated that "information technology is a tool that -if we dare to put it in the citizens' hands - can give us democracy" (Olsson 1999). By that time the theme of associating the Internet with ideas of a stronger democracy was well established. Already a couple of years earlier a senior writer for one of Sweden's largest morning newspapers, Göteborgs-Posten, argued that "IT can become a powerful tool to increase the citizens' opportunities to participate in and to inform themselves about political decisions" (GP 1996). These are but two of the numerous examples of this issue within the Swedish popular debate during the late 1990s and early 2000s.

These simplified projections of a stronger democracy onto the new ICT leave much room for criticism. They can be criticised for extrapolating the medium's social effects from its technological form: the projections move from qualities in the technology - its openness, accessibility, and speed - to conclusions about the use of technology among citizens and, even further, to democratising effects following that use. They can also be criticised for their inability to question the Internet's path into society and for not comprehending the rather obvious fact that the Internet, from the beginning, was hardly developed to make democracy stronger (cf. Nørretranders 1999, Gandy 2002). In short, then, there have been rather obvious technologically deterministic (Williams 1974, MacKenzie and Wajcman 1999, Preston 2001) threads within Swedish popular debates, as well as elsewhere.

Social scientists are by no means innocent in this respect. Although more subtle, technologically deterministic threads can be found in their analyses as well. For instance, Manuel Castells' prominent analysis of contemporary society as a "network society" (Castells 1996-98) has obvious similarities with the view of technology as determining social and cultural outcomes (cf. van Dijk 1999, Webster 2002). In general, however, social science has had a more reflexive approach to the Internet than the popular and policy debates. Most researchers tend to agree that the Internet per se does not bring democratising effects, but that the new ICT, accompanied by the right circumstances and, more importantly, used in the right manner by users, can be (socially and culturally) shaped into a civic tool.

Notwithstanding the fact that social scientists have been less technologically deterministic in their approaches to the Internet, they have had their own shortcomings. For instance, critical political economists have highlighted some problematic, implied propositions in the research on the new media in general and the Internet in particular. Robert McChesney has criticised researchers' tendency to look at the Internet as a new entity rather than as "a part of a historical process and a logical extension of corporate media and communication system" (McChesney 1999, 8). 
Gerald Sussman, on the other hand, has stressed the importance of remembering that the Internet - apart from offering democratising potential - also has strong connections with powerful economic interests (Sussman 1997).

But there are at least two additional shortcomings in the research on the Internet and its democratic implications - shortcomings that serve as the central discussion points for this paper. Firstly, with a few outstanding exceptions (cf. Bakardjieva and Smith 2001, van Zoonen 2002, Bakardjieva 2005), extant research has paid limited heed to everyday users' perceptions and uses of the Internet. Instead, empirical studies into this area have relied heavily on statistical data, predominantly focusing on the differentiated access to the new ICT among various user groups (cf. Hill and Hughes 1998, Wilhelm 2000, Quan-Haase et al. 2002). As such, these studies have neglected how and to what extent the Internet's democratic or civic capabilities are perceived by users in their everyday lives. Such is the case despite the recurring call for studies of the medium's use in concrete everyday settings (Moores 2000).

Secondly, research in the area of Internet and democracy has shown a preference for examining the Internet as an isolated phenomenon. As such, the Internet has not been adequately conceptualised as an element to be incorporated, both spatially and temporally, into the everyday routines of users acting within an established media environment (Silverstone 1994, Sjöberg 2002). In short, existing research into the Internet and democracy has an obvious blind spot when it comes to understanding how the Internet is perceived and how it is used in comparison to the other, "old" or "traditional" media, and how it gets incorporated into users' everyday lives.

Needless to say, these are important deficiencies in our understanding of the Internet as a tool for democracy. This article is a modest effort to compensate for these deficiencies by analysing civic identity with reference to the uses and perceptions of the Internet and traditional media among adults within fifteen Swedish working class households. How important is the Internet to working class individuals' civic identity? And how important are traditional media to their civic identity?

\section{Old Media, the Internet and Civic Identity}

The concept civic identity, as it is used here, draws on Peter Dahlgren's notion of civic culture (Dahlgren 2000; Dahlgren 2003). Dahlgren states that we have become so accustomed to viewing democracy and citizenship in structural terms - that is, in terms of rights, obligations, and formal political structures, etc. - that we tend to forget that citizenship is also rooted in people's lifeworlds, values and everyday practices. Expressed differently, a functioning democracy also presumes a culture that makes that very democracy possible.

Within the framework of civic culture, the concept civic identity suggests that citizenship is not solely about acting as a citizen -i.e., voting, participating in public spheres, attending meetings, etc. - it is also about having a view of oneself as a potential participant in society at large, outside of family relations. This does not, however, mean that citizens need to identify themselves as "citizens" - very few everyday individuals would refer to themselves by using this concept. Instead, the concept refers to having an image of oneself as a part of a wider society, and as a potential participant in that society. As such, the concept refers to a more rudimentary sense of civic identity. 
This notion of civic identity has connections to other ideas within the social sciences, perhaps most notably to the political scientist Robert Putnam's thoughts on social capital (Putnam 2000). It also alludes to Alexis de Tocqueville's (1835/1994) early studies of American democracy. Very much like these scholars, Peter Dahlgren specifically seems to consider affinity to be an important dimension of the identity of the citizen. In Dahlgren's case, affinity seems to refer to citizens' connections to different kinds of communities, both to the politically administrative society as a whole (the municipality, the region, the nation, etc.), and to the smaller communities within that society.

From this point of theoretical departure, the media's contribution to people's civic identity cannot be underestimated. It is almost too modest to claim that the media play an important role in the creation and reproduction of people's views of their civic selves, since they comprise the most important window on the social reality outside the intimate lifeworld. The local morning papers provide insight on current events in their relevant neighbourhoods. The TV offers access to the global news flow and information about distant events, inviting, at its best, reflections on worldwide issues. The national radio stations' continuous coverage of international sporting events beckons listeners to identify with national communities. Numerous other examples exist, but those listed here provide insight into how the traditional media have (at least potentially) contributed to people's civic identities.

But the new ICT, the Internet, also invites the creation and reproduction of people's civic identities. It does so by offering perspectives on society, just as the traditional mass media do, and by offering access to and thus identification with different kinds of Internet-based communities. Regarding the issue of societal perspectives, the Internet's open character enables for instance small and economically weak media actors to reach public attention, thus not confining analyses and debates to that which is produced by established news and information distributors (Meikle 2002).

Further, the Internet's interactive character provides opportunities for users to take part in and identify with various communities. This notion is reminiscent of a long standing theoretical thread within traditional media research (Thompson 1995, Gripsrud 2000). The established discourse suggests that the media allow people to imagine themselves as part of a wider community, and the Internet is by no means an exception. Indeed, the Internet is an ICT with great potential when it comes to community building (Jones 1994; Smith and Kollock 1999; Slevin 2000; Jankowski 2002; Feenberg and Barney 2004).

The Internet can also be said to function as an expansion of established, local communities. In the literature, these communities are often represented by web communities based on a city or a municipal community (Tsagarousianou et al. 1998), but they can just as well be built on other "real life" platforms, like sporting clubs or music associations. But so far, research has centred much of its attention on the Internet as a creator of communities that cross established boundaries of time and space, like fans of alternative pop groups (Watson 1997), or people simply getting together on the Internet (Rheingold 1994).

Obviously, traditional media as well as the new ICT (the Internet) potentially have much to offer in terms of informing people's civic identities. But the question of whether or not the media truly facilitate the shaping of civic identities - and 
whether the Internet is as important to people's civic identities as the traditional mass media - is an empirical question, rather than a question that can be answered by reading the effects of the new ICT from its technological form.

This article, then, argues that it is valuable to empirically study how and through what media different groups of users develop outlooks towards society, and whether or not they use the Internet to keep in touch with various Internet communities. Through what media do they collect their impressions of the world and inspirations to their thoughts about society? How important are the traditional mass media and the new ICT in this respect? And to what extent is the Internet a tool for maintaining contact with various communities?

\section{The Empirical Study}

The empirical study centres on 25 adult respondents (ages 18 to 57) in 15 Swedish working class households with access to at least one computer and to the Internet. Within the wider study upon which this article is based, three methods of data collection where used: semi-structured interviews, observations of household activities, and respondents' media diaries (Olsson 2004a). The data used within the present article is almost exclusively interview data. However, the interview data used here has also been validated by cross checking information from the interviews with information in the respondents' media diaries. The respondents' media diaries have also been used for contextualising the interview answers in some cases.

The semi-structured interviews took place in the respondents' home environments. In households with two or more grown ups, the respondents were interviewed together (in nine households), while the interviews where carried out individually in households with only one grown up person (in six households). The interviews followed a general structure covering four sub fields: 1) biographical information about the respondents (age, family, work etc.), 2) the respondents' use and perception of traditional media, 3) the respondents' use and perception of the computer and the Internet and 4) civic activities. However, for obvious reasons, most of the time was spent on the second and third theme. The interviews usually lasted from about an hour and a half up to two hours and a half. Since the interview sessions - which where recorded on tape and then transcribed - also where preceded by socialising small talk, the household visits usually lasted for about three hours each. Out of the fifteen households, seven where paid only one visit, while eight were visited twice. The second round of visits - and interviews - took place about half a year after the first interviews, and they were conducted in order to develop a couple of themes that analysis of the first round of interviews suggested were especially interesting for further study. All in all, the empirical parts of this article draw on some 50 hours of interview data.

The media diaries were completed by nine of the study's households. All households were asked to do so, but six of them basically asked to be relived from that duty, in most cases due to the fact that it appeared a bit too much of an effort to complete them. Of the respondents appearing in the empirical parts of this article, all households but one (referred to as Patrik, a divorced father of two children in his early thirties) have in fact completed their diaries. The media diaries covered all media use among the grown ups in the households during one ordinary week; 
ordinary in terms of being a regular working week. The respondents made an entry for each media use during that week, stating what medium as well as what content they were using at what time of day. They were also encouraged to continuously comment on their media use as well as the content they encountered. However, just a few of the respondents made use of this possibility.

What about the households then? Although a lack of space prevents a thorough description of the participating households, it is useful to at least touch upon their access to material, social and discursive (Murdock et al. 1992, Warschauer 2003, Golding \& Murdock 2004) resources to better understand the media and Internet users that we have before us. Considered as a group, the 15 working class households appear comfortable in terms of material resources. All of the respondents are gainfully employed, live in fairly high standard apartments or houses, and have expendable income for vacations and automobiles. However, it should be noted that given their occupations - for example, house painters, assistant nurses and carpenters - they do not fit into a high-income profile. With regards to social resources, it is important to note that all of the respondents are fairly active citizens in that they are members of various civic organisations. Finally, the participating households' discursive resources are somewhat limited, at least in formal terms (Bourdieu 1984). An obvious example is the fact that none of the respondents has experience from higher education, and several of them lack education from upper secondary school.

\section{TV or the Internet?}

Among the working class households, the TV is definitely perceived as offering outlooks on society. A comparison between the TV and the Internet makes this obvious: while the TV is perceived as "giving information" and "keeping one upto-date," the Internet is perceived as "a working tool" or "good for the children in their school work." This is also reflected in their use of different media.

The difference in both perception and use of the TV and the Internet becomes especially obvious when it comes to the working class users' opinions and thoughts on society. With no exceptions, the respondents refer to something they have seen on TV rather than read on the Internet when they present their views on all issues ranging from ideological preferences to more sporadic opinions.

This is exemplified through an interview with Bengt (47 years old) and Nina (45), who live in a Stockholm suburb with their three children. Nina, who works in health care, explains that a major problem in using the Internet is that it is just too difficult to handle. On the other hand, she is very keen on news, current affairs programmes and documentaries on the Swedish public service TV channels. She follows the news on a daily basis, and she considers TV documentaries as peaks in her media menu.

The most recent in the long list of documentaries that she has watched is about the closing down of a hospital maternity ward in northern Sweden. She saw that documentary in the evening the day before the interview. Bengt - on the other hand - did not see it. He is generally not that keen on documentaries and, anyhow, as a coach for his son's hockey team, he was at the sports centre at that time, like he is most evenings: 
Nina: It was kind of sad, since they were closing it [the maternity ward] down.

Bengt: Was that the reason why they showed it [on TV]?

Nina: No, not really, that was only a part of the story.

Bengt: But you mean that they no longer have any maternity ward there?

Nina: Yes, and they were also closing down a few more maternity wards nearby.

Bengt: Nearby? Is there such a thing as "nearby" up there [in the northern, hardly populated part of Sweden]?

Nina: No, but they were still closing it down.

Bengt: Wow, then they must have... What?... At least $500 \mathrm{~km}$ to go to the maternity ward!

Nina: Yes, but they were still closing them down. [...]

Interviewer: It did seem rather cosy [at the maternity ward that was about to be closed down].

Nina: Yes, and they all seemed to know each other very well, didn't they?

The most interesting aspect of the extract is not its explicit content - that is, that Bengt has not seen the documentary and therefore questions Nina about it. Rather, most interesting is the short discussion that is generated by Nina's description of the documentary. Her description of the documentary (which both she and the interviewer have seen) turns into a wider reflection on the prerequisites for hospital care in different parts of Sweden. Nina's retelling of the documentary and the ideas that it seems to have provoked triggers a short discussion between herself and Bengt. The discussion reveals that the documentary has not only made Nina reflect on hospital care, but Bengt also starts to reflect on these issues. This discussion, provoked by a TV-programme, contrasts sharply with how they use and perceive the Internet. Bengt has never been able to actually use the Internet and Nina says that she has problems with understanding the "difficult technology."

That the TV is perceived as a resource through which the working class household members obtain outlooks on society is made equally clear in an extract from one of the interviews with Anne and Bertil (50 and 51 years old, respectively). They explain that they follow, on a daily basis, both of the Swedish public service channels' news programmes:

Anne: I guess we've just started to realise that now... We kind of used to laugh at our parents when they went: "I watched the news at six o' clock, then I watched them at half past eight and then again at nine o'clock." But now, we're starting to do that as well.

Bertil: Yes, somehow... as we grow older... these news programmes have become more and more important. One tends to want to see them.

Anne: Yes, something could have happened during the last two hours... [laughter]

Bertil: Yes... Well... They do put different angles on the news [...]

Anne: But sometimes I can think that I've just had it with a piece of news.

Bertil: Yes, of course, but still they tend to angle it differently. I find that very interesting. 
In the extract, Bertil and Anne's rather heavy consumption of TV news is made evident. Every day they watch the news, and sometimes on two, or even three different channels. They also follow current affairs programmes. Needless to say, their TV-set appears to be an important window to the world outside. Interestingly too, both of them use an inclusive "we" as they talk about their media habits in general and their TV habits in particular. With few exceptions they obviously watch all these TV news together, sitting in their living room sofa, and they have quite evidently also reflected on this habit at several occasions; they pretty much speak with one voice in their retelling of their media habits.

However, due to their consumption of TV news it comes as no surprise that they refer to things they have seen or heard on TV when they express their opinions on various issues. For instance, Bertil makes clear that he questions the lowering of income taxes, a policy presented in the local news a few days before the interview. Anne, on the other hand, says that she is worried about and puzzled by the reports on the tough real estate market in Stockholm, and that so many young people have a hard time finding places to live.

The ideas and outlooks on society that Bertil and Anne present reveal interesting aspects of their civic identities. Firstly, they are certainly up to date on most current issues, presumably from their rather heavy consumption of TV news. Secondly, they are also able to reflect upon and present opinions on various current events, from taxation to the real estate market. Thirdly, Anne and Bertil's consumption of TV news and current affairs programmes on TV have much more to do with their civic identities than their use of the computer and the Internet. While the TV news and the current affairs programmes are well incorporated into their everyday lives - something that they routinely watch together - the Internet is used only occasionally to search for very specific information, like when they are making travel plans.

\section{Newspapers Rather Than the Internet}

It is not only through the TV that the adults in the working class households keep updated on - and perceive themselves as being updated on - the world around them. The newspapers also seem to bring this sense of belonging to society at large. The extract below from an interview with Tom and Maria, a married couple in their mid thirties with two children, makes this obvious.

Interviewer: What are newspapers good for?

Tom: To me they are relaxation, but also information and advertisement, but that's not so important [advertisement]. It's mostly information... And if something special has happened I usually buy a paper to check it up, I usually buy several papers. I'd say that papers are news, but slow news.

Interviewer: And what about the TV then?

Tom: It's more immediate...

Maria: ...yes...

Tom experiences the computer and the Internet as extremely difficult to handle. He thinks that his problems with using the new ICT are connected to his reading 
and writing disability. He thus seldom, if ever, uses the Internet to keep up to date on current events. Instead, as reflected in the interview extract, Tom (who is very interested in politics) uses newspapers to stay current. The newspaper is "slow news" he says, but something he turns to "the day after" something has happened. Maria, on the other hand, does not find the computer as difficult as Tom does. However, in other parts of the interviews she makes clear that she does not make much use of the computer either. Instead, just like her husband she prefers reading newspapers and watching TV news in order to stay up to date.

The fact that newspapers rather than the Internet are used for keeping up to date on current events within the working class households is equally obvious in the case of Anne and Bertil. In short, their civic identities have a lot more to do with their everyday reading of newspapers and watching of TV (above) than with their occasional use of the Internet:

\begin{abstract}
Anne: But all this... Sometimes what you read in the morning is really news, but sometimes the papers just repeat what you heard on TV the evening before. But I think that I... I think that I'm more into the cultural news than you [Bertil] are. If there is a new movie, or they put on a new play at the theatre, I usually read the reviews.

Interviewer: So... if one was to make a distinction between the two of you when it comes to newspaper reading, then the morning paper is mainly"news" to you [Bertil], but something more than news to you [Anne]...
\end{abstract}

Bertil: Yes, that pretty much sums it up.

The extract certainly shows to what extent Bertil's and Anne's reading of the morning newspaper has become a routine of their everyday lives - they tend to read pretty much the same parts of the newspaper every day and have their own, individual interests. But it also illustrates to what extent the newspaper is perceived as keeping them current on society at large. It complements their heavy use of TV news (above).

This contrasts sharply with their perception of the computer and the Internet:

Anne: [F]irst we have to get down on the floor to plug in the computer cable. Then we have to wait while the computer starts up, and then we have to double click on the Internet icon and wait while the computer tries to connect to the Internet and - of course - it usually fails on the first attempt...

Bertil: Yes, [it fails] because the server is occupied...

Anne: ....and then it doesn't work on the second attempt either, but perhaps on the third and then it has taken you almost ten minutes and that's... I think...

Bertil: Well, usually one isn't in such a hurry...

Anne: No, not really, but it still feels way too complicated, it really does. So I usually try to wait until I have several things to do until I finally use the Internet. I never go to the Internet in order to do just one thing, instead I wait until I can do several things at once.

While newspapers are well integrated into the routines of everyday life, and thus have become a natural part of the media environment, the new ICT is rarely used and is considered technically difficult or impractical. We can also note- once again - how unanimous Anne's and Bertil's practises and perceptions are. They tend to consume media in a very similar manner - most often together with one 
another - and they also perceive their various media in very similar ways. Both Anne and Bertil are very much into news media, but very little into the expensive computer with internet connection that is located in their bedroom.

\section{Radio Instead of the Internet}

Obviously, as a consequence of the limited use of the new ICT, references to "the Internet" are almost completely absent when it comes to the respondents' reflections on and thoughts about society. Instead, they refer to things they have seen on TV and read in the newspapers. But the radio also seems to fit into this pattern of using "old" media rather than "new media" for keeping updated on societal issues.

Patrik, who is in his early thirties and a divorced father of two children, lives by himself. On a question about his societal engagement he says that he is "genuinely uninterested" in society at large, and that he "hates politics." Nevertheless he admits, after repeated questions by the interviewer, that he of course follows societal developments, at least to some extent. However, he does not read newspapers and he does not follow the news on TV, but he listens to the radio both at work and at home:

\footnotetext{
Interviewer: So you just might be at least slightly interested in what is going on in society?

Patrik: Well, I guess so. But I don't... I'm not interested or engaged in it [the society] or anything like that, but you can't really avoid it. I hear about it all the time on the radio, it's impossible to escape it, so to speak.
}

Even though Patrik tries to avoid getting engaged in society, the radio keeps him connected. As a result of his radio listening habit, popular debates and current issues trickle into his everyday life and make him reflect on current events. So even though Patrik tries not to develop a civic identity, the radio forces him to do so, at least to some extent. This is the opposite to his use of the computer - he hardly ever uses it, and on the few occasions when he does, he downloads music or plays computer games. The computer, he says, was mostly obtained in order to make sure that his children were able to practise computer skills for school.

\section{Exceptions from the Overarching Pattern}

The overall pattern emerging from the above empirical material is that traditional media usage offers a sense of belonging to, and outlooks towards, the society of which the respondents are a part. On the other hand, the respondents' civic identities seem to have very little, if anything, to do with their use of the Internet.

However, the empirical material offers a couple of exceptions. For example, one of the respondents, Karoline, a 35 years old mother of two, says that she uses the Internet to catch up on the news. She does so in order to do better in her adult education courses, where she is often tested on her knowledge of current events. Hence, she spends many late nights in front of the computer screen. Her husband, however, emphasises that he only uses the computer for tracking down information about his favourite artists. Another respondent, Pia, a middle aged single woman 
in a small village near Stockholm, sometimes reads the news on the Internet when she has missed the news on TV.

Notwithstanding these exceptions, the overall theme - that the respondents' civic identities are to a greater extent cultivated by their use of traditional media than the new ICT - remains intact. This is underscored through another quote from the couple Bengt and Nina (above):

\footnotetext{
Bengt: Well, I guess that we could read the newspaper on the Internet instead of buying it.

Nina: That sounds awfully boring, don't you think?

Bengt: Yes, of course. But I'm just suggesting that's something we could do [not something that we should do].

Nina: Well... yes... I suppose that's something that we could do.
}

In the extract Bengt suggests to his wife that they could start reading the newspaper on the Internet rather than in hard copy form, as a way of increasing their Internet usage. At another stage in the interview they have both agreed on the fact that it is quite a waste of money to have a computer with Internet access without ever using it (however, their children tend to use it when they need it for homework in school or for playing computer games). But Nina's reaction to Bengt's suggestion - that it "sounds awfully boring" - triggers Bengt to retract his proposition. He says that he is only making a suggestion about what they perhaps could do, rather than what they should do. In any case, it does seem to be a stretch for them to start orienting themselves toward current events through the Internet.

\section{"Communiting" on the Internet?}

Obviously, the opportunities offered by the Internet for keeping up with societal developments are not to any great extent appropriated by the Swedish working class users included in the study. Instead, they tend to adhere to the traditional, "old" media for that purpose.

Importantly, however, the interactive design of the new ICT does facilitate possibilities for the cultivation of identity that the old media cannot compete with: it offers access to and identification with various Internet-based communities. But due to the low degree of general Internet usage among the working class households studied, the results are disappointing, at least from the perspective of those who have put their trust in the Internet to make democracy stronger. While most of the households are active participants in various associations within civil society, such as sports clubs or music associations, and in some cases they are even very much involved, the Internet does not seem to be in any way related to these civic activities.

The interview with Tom (again) provides an obvious example. Until a couple of years ago, Tom was an elite athlete. Although he has stopped competing, he is still involved in his sport as a coach and trainer for young athletes. He was for some time also chairman of his club, despite his young age (he and his wife are in their mid thirties). But on the immediate question of how he uses the Internet to engage with his club, and within sports in general, he answers: 
Tom: Well, our treasurer has a computer for making bills and things like that... So... I guess that the treasurer uses it.

Interviewer: I was thinking of contacts between the members, don't you ever use the Internet for that purpose?

Tom: No, of course we never use the computer for such purposes.

While Tom indicates that the Internet might be important for the treasurer's work, he does not see how it is useful in other respects. Instead, his answer to the interviewer's tag question about how the Internet could be used to facilitate member contacts indicates that he conceives the idea as somewhat senseless. Why would anyone use the Internet to maintain contacts with the club?

Tom's limited use of the Internet can at least be partially explained by the fact that he has problems using it and has limited reading and writing skills. But on the whole, and for the other interview respondents, these reasons cannot explain why the Internet is not shaped into a tool for organisational coordination and for maintaining community contacts. Annica, a 45-year-old single mother of two children, often uses the computer at work. Thus, she is by no means an inexperienced user. In spite of this, she has never considered using the Internet for contacting members and coordinating activities for her local dancing club, even though she spends a lot of time every week on voluntary work within the organisation. The same goes for Pia, a 55-year-old divorced woman and mother of two adult children. She uses computers and the Internet at work on an everyday basis, but she has never really reflected on the value of incorporating them into her activities within the local bowling club by, for instance, e-mailing.

The fact that the Internet is not converted into an ICT for civic activities among the working class users is thus well-evidenced by their failure to use the Internet in communicating with online communities. Access to a computer with an Internet connection - which opens up possibilities for participation in various kinds of Internet communities like mailing lists and news groups - does not have any practical significance to these working class users in their everyday lives.

\section{Concluding Remarks: Mind the "Old" Media}

Needless to say, reflecting on these results we have a strong case for suggesting that, firstly, the traditional media are much more important than the Internet when it comes to the respondents' civic identities; and secondly, that the opportunities for civic engagement that are unique to the Internet are rarely appropriated. Thus, from the point of view of the empirical material presented here, we might say that the Internet seems to be a rather marginal resource in the development of working class users' civic identities.

Of course, it is always somewhat risky to generalise from a small number of respondents, and perhaps even more so when the respondents represent a very specific set of media users. The results and their analysis would of course differ if they were based upon a study of, say, upper middle class or politically active respondents (Olsson 2004b). Among these sets of Internet users, the new ICT might be more heavily incorporated into their everyday lives, and they might even use it in a more civic-oriented manner than this study's respondents. 
Notwithstanding the possibility of finding other groups of users for which the Internet is a more important medium, this study's data are still, I suggest, valuable. And interestingly, comparison between these data and contemporary statistical studies on the use of traditional media and the Internet (cf. Nordicom 2003; Nordicom 2004) reveals a similar pattern: Working class people are not the heaviest users of the Internet in terms of time spent online. Furthermore, the statistical analyses indicate that among all classes of user groups (i.e., not only among the working class), more time is spent consuming traditional media such as TV, newspapers and radio than the new ICT. These tendencies - which have remained somewhat stable within the statistical studies over the years (ibid.) - have certainly been validated and also further substantiated by the empirical material presented here. That is, this article reveals that the marginal use of the Internet is not merely a matter of lack of time spent online, but it also seems to be a matter of how the new ICT is perceived among the users in comparison with the traditional media. While the traditional media are perceived as offering outlooks on society, the Internet is to a far lesser extent associated with keeping updated on, for instance, news and current events.

The importance of these findings is, I suggest, at least twofold. Firstly, the findings are important to policy makers interested in understanding the role of the media and the new ICT for democracy. The results should function as a reminder of the fact that the Internet is not necessarily, or inherently, a resource for the development of civic identities. Instead, efforts are needed in order to shape the new ICT into a civic tool. One example of such efforts is the development state funded education on how to use the Internet. Education could make even this study's working class users more likely to utilise the Internet, and could help them to use it in a more encompassing, and perhaps even civic, manner (Raboy et al. 2003, Olsson et al. 2003). For policy makers the results should also function as a reminder of the fact that while the policy agenda - at least within the Swedish context - has focused rather narrowly on the new ICT as a "democratic tool," the traditional media still play an important role in people's everyday lives. Thus, the heavy policy focus on the new ICT must not mean that efforts to shape the Internet into a "democratic tool" are accompanied by a withdrawal from such ambitions in the area of traditional media.

Secondly, the results are important to the media research community. To start with, they serve as a reminder of the importance of sceptically viewing the inflated expectations (and also, the fears) that come with the introduction of a new ICT into society. Media research should rely on its long experience studying new media in everyday settings - and studying the new media's incorporation into an established media environment - in its efforts to estimate the significance of new ICTs. Such research traditions certainly make it clear that the established routines of everyday life are not easily altered, and thus serve to mediate any possible immediate effects of new media on, for instance, people's civic identities.

A related issue actualised by this study's results is the value of not designing audience research projects that focus solely on one medium (Livingstone 2004). In attempting to understand the significance of a new ICT, or any other everyday medium, we should carefully demarcate the given medium as merely one within a larger media environment. In doing so, the media being studied can, to some extent, be viewed as competitors for the users' attention and preference. 
Finally, it is worth noting that for some, the ideas presented in this paper are all but revolutionary. Most media scholars would likely agree with them, and may even consider them to be somewhat self-evident. Despite this, research on the Internet and democracy has failed to adequately address these ideas. Within existing research - which has been inundated by scholars from various disciplines (e.g., computer science, philosophy, history and political science) - there has been a tendency to look upon the Internet as a novelty, rather than as just another new medium. As a result, there has been a reluctance to draw upon established research approaches to the media. Further, with few exceptions, the most common approach has been to study the Internet in isolation, as opposed to viewing it as a new medium trying to find its place among the users' existing media environments.

The issues raised in this article cannot be made too evident, and perhaps as scholars within the field of media research we have a certain responsibility to emphasise them. It might very well be our job to point other researchers from other disciplines in the direction of this knowledge. And importantly, it is likely our role to highlight this knowledge for policymakers who naively believe that - by simply putting the Internet in the hands of citizens - they can inspire democratic development.

\section{References:}

Bakardjieva, Maria. 2005. Internet Society: The Internet in Everyday Life. London: Sage.

Bakardjieva, Maria and Richard Smith. 2001. The Internet in Everyday Life: Computer Networking From the Standpoint of the Domestic User. New Media and Society 3, 67-84.

Bourdieu, Pierre. 1984. Distinction. A Social Critique of the Judgement of Taste. London: Routledge \& Kegan Paul.

Castells, Manuel. 1996-98. The Information Age: Economy, Society and Culture. 3 Vols. Malden: Blackwell Publishers.

Dahlgren, Peter. 2000. Media, Citizenship and Civic Culture. In J. Curran and M. Gurevitch (eds.), Mass Media and Society, 310-328. London: Arnold.

Dahlgren, Peter. 2003. Reconfiguring Civic Culture in the New Media Milieu. In J. Curran and D. Pels (eds.), Media and the Restyling of Politics: Consumerism, Celebrity and Cynicism, 151-170. London: Sage.

van Dijk, Jan. 1999. The One-dimensional Network Society of Manuel Castells. New Media and Society $1,127-138$.

Gandy, Oscar. 2002. The Real Digital Divide: Citizens Versus Consumers. In L. Lievrouw and S. Livingstone (eds.), The Handbook of New Media, 448-460. London: Sage.

GP. 1996. Demokrati med IT kan bli ett instrument för en bättre demokrati. Editorial page. GöteborgsPosten, 14 March 1996.

Feenberg, Andrew and Darin Barney, eds. 2004. Community in the Digital Age. Lanham: Rowman \& Littlefield Publishers.

Golding, Peter and Graham Murdock. 2004. Dismantling the Digital Divide: Rethinking the Dynamics of Participation and Exclusion. In A. Calabrese and C. Sparks (eds.), Toward a Political Economy of Culture, 244-260. Lanham: Rowman \& Littlefield Publishers.

Gripsrud, Jostein. 2002. Understanding Media Culture. London: Arnold.

Hill, Kevin and John Hughes. 1998. Cyberpolitics: Citizen Activism in the Age of the Internet. Lanham: Rowman and Littlefield.

Jankowski, Nicholas W. 2002. Creating Community with Media: History, Theories and Scientific Investigations. In L. Lievrouw and S. Livingstone (eds.), The Handbook of New Media, 34-49. London: Sage.

Jones, Steven, ed. 1994. CyberSociety: Computer-Mediated Communication and Community. Thousand Oaks: Sage. 
Livingstone, Sonia. 2004. The Challenge of Changing Audiences: Or, What is the Audience Researcher to do in the Age of the Internet. European Journal of Communication 19, 75-86.

MacKenzie, Donald and Judy Wajcman, eds. 1999. The Social Shaping of Technology. 2nd ed. Buckingham: Open University Press.

McChesney, Robert. 1999. Rich Media, Poor Democracy: Communication Politics in Dubious Times. Urbana: University of Illinois Press.

Meikle, Graham. 2002. Future Active: Media Activism and the Internet. Annadale: Routledge.

Moores, Shaun. 2000. Media and Everyday Life in Modern Society. Edingburgh: Edingburgh University Press.

Murdock, Graham, Paul Hartmann and Peggy Grey. 1992/1994. Contextualizing Home Computing: Resources and Practices. In R. Silverstone and E. Hirsch (eds.), Consuming Technologies: Media and Information in Domestic Spaces, 146-160. London: Routledge.

Nordicom. 2003. Mediebarometer 2002. Göteborg: Nordicom.

Nordicom. 2004. Mediebarometer 2003. Göteborg: Nordicom.

Nørretranders, Tor. 1998. Platsen som inte finns: En bok om Internet. Stockholm: Bokförlaget DN.

Olsson, Anders. 1999. Alla måste anslutas till internet: Ny statlig utredning: datortekniken är enda sättet att stärka den svenska demokratin. Dagens Nyheter, 15 March 1999.

Olsson, Tobias. 2004a. IT-visioner möter IT-vardag: Om politisk kommunikation i retorik och praktik. Sundsvall: Demokratiinstitutet.

Olsson, Tobias. 2004b. Oundgängliga resurser: Om medier, IKT och lärande bland partipolitiskt aktiva ungdomar. Lund: Lund Studies in Media and Communication.

Olsson, Tobias, Håkan Sandström and Peter Dahlgren. 2003. An Information Society for All? Gazette 65, 347-364.

Preston, Pascal. 2001. Reshaping Communications: Technology, Information and Social Change. London: Sage.

Putnam, Robert. 2000. Bowling Alone: The Collapse and Revival of American Community. New York: Simon and Schuster.

Quan-Haase, Anabel and Barry Wellman with James Witte and Keith Hampton. 2002. Capitalizing on the Net: Social Contact, Civic Engagement, and the Sense of Community. In B. Wellman and C. Haythornthwaite (eds.), The Internet in Everyday Life, 291-324. Oxford: Blackwell Publishing.

Raboy, Marc, Serge Proulx and Peter Dahlgren. 2003. The Dilemma of Social Demand. Gazette 65, 323-330.

Rheingold, Howard. 1994/1999. The Virtual Community. In H. Mackay and T. O'Sullivan (eds.), The Media Reader: Continuity and Transformation, 273-286. London: Sage.

Silverstone, Roger. 1994. Television and Everyday Life. London: Routledge.

Sjöberg, Ulrika. 2002. Screen Rites: A Study of Swedish Young People's Use and Meaning-Making of Screen-Based Media. PhD thesis. Lund: Lund University, Department of Sociology.

Slevin, James. 2000. The Internet and Society. Cambridge: Polity Press.

Smith, Mark and Peter Kollock, eds. 1999. Communities in Cyberspace. London: Routledge.

Sussman, Gerald. 1997. Communication, Technology and Politics in the Information Age. Thousand Oaks: Sage.

Thompson, John B. 1995. The Media and Modernity: A Social Theory of the Media. Cambridge: Polity Press.

de Tocqueville, Alexis. 1835/1994. Democracy in America. Ed. G. Lawrence. London: Fontana.

Tsagarousianou, Roza, Damian Tambini and Cathy Bryan, eds. 1998. Cyberdemocracy: Technology, Cities and Civic Networks. London: Routledge.

van Zoonen, Lisbet. 2002. Gendering the Internet: Claims, Controversies and Culture. European Journal of Communication 17, 5-23.

Warschauer, Mark. 2003. Technology and Social Inclusion: Rethinking the Digital Divide. Cambridge: MIT Press.

Watson, Nessim. 1997. Why We Argue About Virtual Community: A Case Study of the Phish.Net Fan Community. In S. Jones (ed.), Virtual Culture: Identity and Communication in Cybersociety, 102-132. Thousand Oaks: Sage. 
Webster, Frank. 2002. Theories of the Information Society. Second edition. London: Routledge.

Wilhelm, Anthony. 2000. Democracy in the Digital Age: Challenges to Political Life in Cyberspace. New York: Routledge.

Williams, Raymond. 1974. Television: Technology and Cultural Form. London: Fontana/Collins. 